\title{
Erratum to: Surgical resection of fourth ventricular ependymomas: case series and technical nuances
}

\author{
Ethan A. Winkler ${ }^{1} \cdot$ Harjus Birk $^{1} \cdot$ Michael Safaee $^{1} \cdot$ John K. Yue $^{1} \cdot$ John F. Burke $^{1}$ • \\ Jennifer A. Viner ${ }^{1} \cdot$ Melike Pekmezci $^{2} \cdot$ Arie Perry $^{2} \cdot$ Manish K. Aghi ${ }^{1} \cdot$ \\ Mitchel S. Berger ${ }^{1} \cdot$ Michael W. McDermott $^{1}$
}

Published online: 30 December 2016

(C) Springer Science+Business Media New York 2016

\section{Erratum to: J Neurooncol (2016) 130:341-349 \\ DOI 10.1007/s11060-016-2198-6}

The video published online as supplementary material to the original article was incorrect. The correct video is published online as supplementary material to this erratum.

Electronic supplementary material The online version of this article (doi:10.1007/s11060-016-2343-2) contains supplementary material, which is available to authorized users.

The online version of the original article can be found under doi:10.1007/s11060-016-2198-6.

Michael W. McDermott

Mike.McDermott@ucsf.edu

1 Department of Neurological Surgery, University of California San Francisco, 505 Parnassus Avenue, M-779, San Francisco, CA 94143-0112, USA

2 Deparmtent of Pathology, Neuropathology Unit, University of California San Francisco, San Francisco, CA, USA 